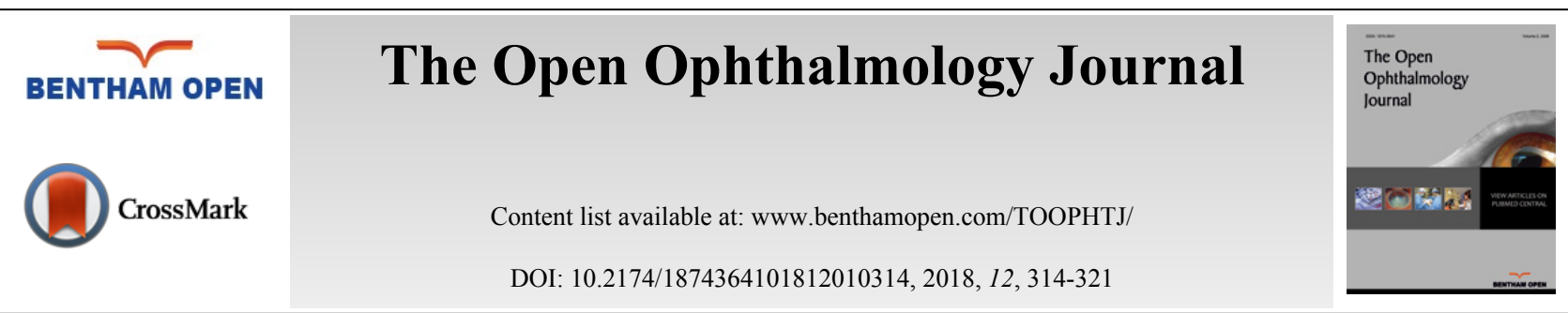

RESEARCH ARTICLE

\title{
Effect of Acute Increases in Intraocular Pressure on Corneal Pachymetry in Rabbit Eyes Treated with Timolol Maleate
}

\author{
Cristina Sánchez-Barahona ${ }^{1}$, Gema Bolívar ${ }^{2 *}$, Dimitrios G. Mikropoulos ${ }^{3}$, Anastasios G. Konstas ${ }^{3,4}$ \\ and Miguel A. Teus ${ }^{2,5,6}$ \\ ${ }^{I}$ Department of Ophthalmology, Hospital Universitario de Getafe, Madrid, Spain \\ ${ }^{2}$ Department of Ophthalmology, Hospital Universitario Príncipe de Asturias, Alcalá de Henares, Spain \\ ${ }^{3} 3 r d$ University Department of Ophthalmology, Aristotle University of Thessaloniki, Thessaloniki, Greece \\ ${ }^{4} 1$ st University Department of Ophthalmology, Aristotle University of Thessaloniki, Thessaloniki, Greece \\ ${ }^{5}$ Department of Ophthalmology, Clínica Novovisión, Madrid, Spain \\ ${ }^{6}$ Department of Ophthalmology, Universidad de Alcalá, Alcalá de Henares, Spain
}

Received: August 7, 2018

Revised: October 23, 2018

Accepted: November 24, 2018

\section{Abstract:}

\section{Objective:}

To evaluate in an IQYIYR $\amalg$ rabbit model, the effect of topical timolol maleate therapy on the central corneal thickness response to acute intraocular pressure increases.

\section{Method:}

In this prospective and interventional controlled study, the central corneal thickness and intraocular pressure were measured in vivo in 12 rabbit eyes treated with topical timolol maleate for 1 month and in 12 controls at baseline, and after the intraocular pressure (measured by direct cannulation of the anterior chamber) was increased to 15 and $30 \mathrm{mmHg}$ using a forced saline infusion into the anterior chamber.

\section{Results:}

There were no significant differences in the basal central corneal thickness values (control group, $373.2 \pm 12.9 \mu$ m; study group, $377.5 \pm 19.2 \mu \mathrm{m}, p=0.5$ ) or the central corneal thickness values when the intraocular pressure was increased to $15 \mathrm{mmHg}$ (control group, $335.2 \pm 14.3 \mu \mathrm{m}$; study group, $330.0 \pm 32.1 \mu \mathrm{m}, p=0.6$ ) and to $30 \mathrm{mmHg}$ (study group, $318.8 \pm 25.3 \mu \mathrm{m}$; control group, $329.8 \pm 21.0 \mu \mathrm{m}, p=0.3)$.

\section{Conclusion:}

Rabbit corneas treated with topical timolol maleate for 1 month did not show a strain response to acute intraocular pressure increases that differed from control eyes. This is in contrast to a previous finding in which rabbit eyes treated with prostaglandin analogues had a greater decrease in central corneal thickness in response to a sudden intraocular pressure increase compared with untreated corneas.

Keywords: Beta-blockers, Prostaglandins, Cornea, Intraocular pressure, Corneal thickness, Timolol maleate.

\section{INTRODUCTION}

Glaucoma, the second leading cause of visual loss wordwide [1], is an acquired optic neuropathy with progressive retinal ganglion cellular death that leads to irreversible visual field loss [2].

\footnotetext{
* Address correspondence to this author at the Hospital Universitario Príncipe de Asturias, Carretera de Alcalá-Meco s/n. CP. 28805, Alcalá de Henares, Spain; Tel: +34 6469350 77; E-mail: gemabolivardemiguel@yahoo.es
} 
Increased Intraocular Pressure (IOP) is one of the most important risk factors for glaucoma development, and the only effective treatment is lowering of the IOP. Therefore, the accuracy of the IOP measurement is of paramount importance. Goldmann Applanation Tonometry (GAT) is the current gold standard for IOP measurement [3]. It is well known that some corneal characteristics, such as the Central Corneal Thickness (CCT), clearly affect the accuracy of the GAT IOP measurements [4]. In addition, corneal biomechanical properties, such as Young's modulus of elasticity, might have a greater impact on IOP measurements than the CCT [5]. Furthermore, glaucoma can modify the cornea. The posterior corneal surface is more elevated in patients with glaucoma than in healthy subjects [6], lowering the IOP in steroid-induced glaucoma decreases the posterior corneal elevation and the CCT [7] and IOP elevation produces refractive changes in patients who underwent a previous corneal laser refractive surgery [8].

The corneal biomechanical properties determine the response of the corneal tissue when stress is exerted on the tissue [9]. There are different ways to analyze the corneal biomechanical behavior [10 - 12] and, recently, several devices designed to evaluate some of these properties in vivo, such as the Ocular Response Analyzer (ORA) (Reichert Technologies, Depew, NY) and the Corvis ST (Oculus, Arlington, WA), have become available to clinicians [13].

Some antiglaucoma drugs affect the cornea. Topical Carbonic Anhydrase Inhibitors (CAIs) might cause corneal edema when instilled on susceptible corneas [14], and these drugs seem to induce a slight increase in the CCT in normal corneas [15]. In an animal model, we found that topical CAIs affect the Intrastromal Corneal Pressure (ICP) [16], as do alpha-2 agonists, although to a much lesser degree [17].

However, Prostaglandin (PG) analogues induce a slight decrease in the CCT in humans [18] and affect the corneal biomechanical properties, i.e., topical use of these agents increases the Corneal Hysteresis (CH) [19]. In a previous study of our group, we showed that PG analogues modify the corneal strain response (decrease in CCT) in response to acute IOP increases in an animal model [2]. To further investigate if these biomechanical effects are related to the IOPlowering effect of PGs or result from the direct effect of these drugs on the corneal collagen structure, we evaluated the effect of treatment with other topical antiglaucoma drugs, such as timolol maleate, on the corneal response to acute IOP increases in rabbit eyes.

\section{MATERIAL AND METHODS}

This was a prospective, interventional, controlled study. We recorded the IOP and increased the IOP level following exactly the same protocol that we described previously [2]. The experiments were performed in the eyes of male New Zealand rabbits (weight, $2.5-3.5 \mathrm{~kg}$ ). The animals were treated according to the current regulations on experimentation and animal protection of the Government of Spain (RD 53/2013) and the recommendations of the Council of Europe agreement (ETS 123). Topical 0.5\% timolol maleate (Timoftol, Merck Sharp \& Dohme de España, S.A., Madrid, Spain) was instilled in the right eyes of 12 rabbits twice daily (morning and evening) for 1 month. Artificial tears (Acuolens, Alcon Cusí S.A., Barcelona, Spain) were instilled twice daily in the left control eyes of the rabbits. The investigators who performed the experiment did not know which rabbit eyes were treated with timolol maleate or artificial tears, so the measurements were obtained in a masked fashion. All rabbits were anesthetized with a mixture of ketamine $1 \mathrm{~mL} / \mathrm{kg}$ (Imalgene, Merial Laboratory, Lyon, France), xylazine $0.75 \mathrm{~mL} / \mathrm{kg}$ (Rompun, Bayer AG, Leverkusen, Germany), and intramuscular atropine. A topical anesthetic agent (Colicursí Anestesico Doble, Alcon Cusí) was instilled at the beginning of the experiment and supplemental doses were administered every 10 minutes in both eyes. The rabbits were euthanized after the experiment was completed.

The basal CCT and IOP values were recorded in both eyes after anesthesia was induced. The measurements were obtained using the DGH 550 Pachette 2 ultrasound pachymeter (DGH Technology, Inc., Exton, PA), and the average of 10 pachymetry measurements obtained automatically served as the CCT value for each eye. The basal IOP was measured using the Tono-Pen XL tonometer (Medtronic, Jacksonville, FL). The average of three consecutive measurements served as the basal IOP of each eye. The anterior chamber then was cannulated using a winged infusion set with a 27 -gauge needle filled with $0.9 \%$ sodium chloride; the needle was inserted into the anterior chamber through the paralimbic sclera and cyanocrylate glue was applied to the entry point to ensure water tightness. The IOP was measured by manometry using a pressure transducer (MLT0390 Reusable BP transducer, Power Lab, AD Instruments, Racine, WI), which has a pressure measurement range from -80 to $+380 \mathrm{mmHg}$ and an accuracy of $\pm 1 \mathrm{mmHg}$. The transducer is an external sensor for coupling to the IOP in the anterior chamber via a saline-filled silicone tube attached to the catheter (the winged infusion set), and it is connected to an amplifier (ML110 Bridge Amplifier, AD Instruments), allowing direct pressure measurement at the anterior chamber (Fig. 1). The transducer was prepared according to the manufacturer's instructions to ensure a tight seal and that all air was flushed from the system. The 
recorder was set to 0 to initialize the transducer. Before starting the procedure, the transducer was checked to verify correct pressure registration. All instruments, tubes, and needles used in all experiments had exactly the same characteristics, including length and diameter. A second 21-gauge catheter was inserted into the anterior chamber and sealed in the same way. This cannula was connected to an external water column from which variable pressure increases could be induced. In this experiment, constant pressure was generated through a sphygmomanometer wrapped around a water reservoir to stabilize the IOP at $15 \mathrm{mmHg}$ for 5 minutes and then at $30 \mathrm{mmHg}$ for another 5 minutes. Before starting the experiment, a valve between the cannula and the water column blocked the water passage into the inner ocular space. The valve was opened and the pressure in the anterior chamber increased because of the water head.

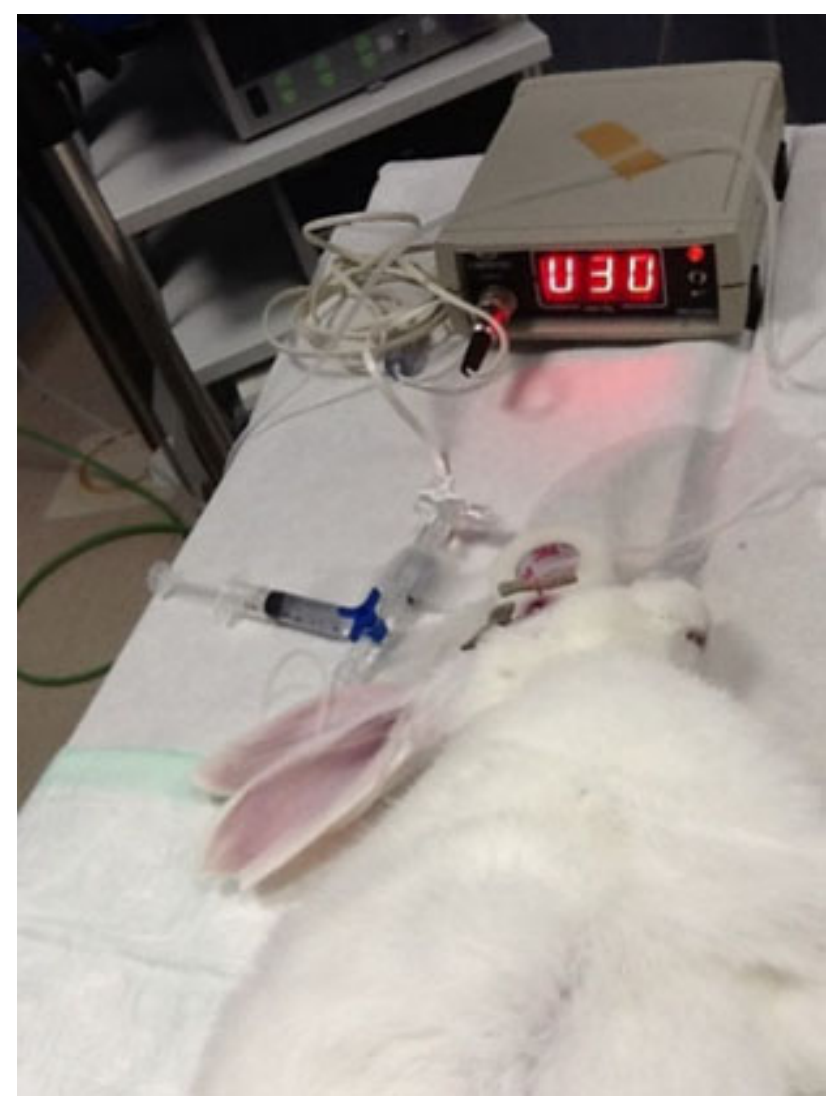

Fig. (1). The figure shows the IOP measurement in the eye of a New Zealand rabbit by direct cannulation with a 27-guage cannula, after setting the IOP at $30 \mathrm{mmHg}$ using forced infusion of saline to the anterior chamber.

The CCT measurements were performed again in both eyes of each rabbit 5 minutes after the anterior chamber pressure was increased to $15 \mathrm{mmHg}$ and again 5 minutes after the IOP was increased to $30 \mathrm{mmHg}$. All eyes were instilled with a saline solution to prevent corneal drying throughout the experiment.

The right or the left eye of each rabbit was chosen randomly to begin the sequence of measurements. The same masked investigator recorded all measurements in the same manner during the afternoon (3 to 6 PM) in every eye. Statistical analysis was performed using the StatView SE + Graphics (Abacus Concepts Inc., Berkeley, CA) software on a Macintosh PowerBook 1400 cs/117 (Apple Computer Inc., Cupertino, CA) personal computer. The data are expressed as the average \pm standard deviation and range. The nonparametric Mann-Whitney and Wilcoxon signed-rank tests were used for comparisons when appropriate. The exact $p$-value is expressed for each comparison. $p<0.05$ was considered significant.

\section{RESULTS}

Measurements were obtained from the study eyes and control eyes of all $12 \mathrm{New}$ Zealand rabbits. The mean basal IOP values before anterior chamber cannulation were $10.10 \pm 3.6$ and $12.0 \pm 2.10 \mathrm{mmHg}$ in the study and control eyes, respectively. The difference in basal IOP between the groups was not significant $(p=0.1)$. 
The mean basal CCT values before anterior chamber cannulation were $377.5 \pm 19.2$ and $373.2 \pm 12.9 \mu \mathrm{m}$ in the study and control eyes, respectively, a difference that was not significant $(p=0.5)$. Five minutes after the anterior chamber pressure was stabilized at $15 \mathrm{mmHg}$, the CCT values decreased in both groups; the mean CCT decreased to $335.2 \pm 14.3$ and $330.0 \pm 32.1 \mu \mathrm{m}$ in the control and study eyes, respectively ( $\mathrm{p}=0.002$ for both comparisons). Five minutes after the IOP was stabilized at $30 \mathrm{mmHg}$, the mean CCT measurements decreased to $318.8 \pm 25.3$ and $329.8 \pm$ $21.0 \mu \mathrm{m}$ in the study and control eyes, respectively (No significant differences were seen in the mean CCT measurements between the study and control eyes at either IOP level ( $p=0.6$ and $p=0.3$, respectively) (Fig. 2).

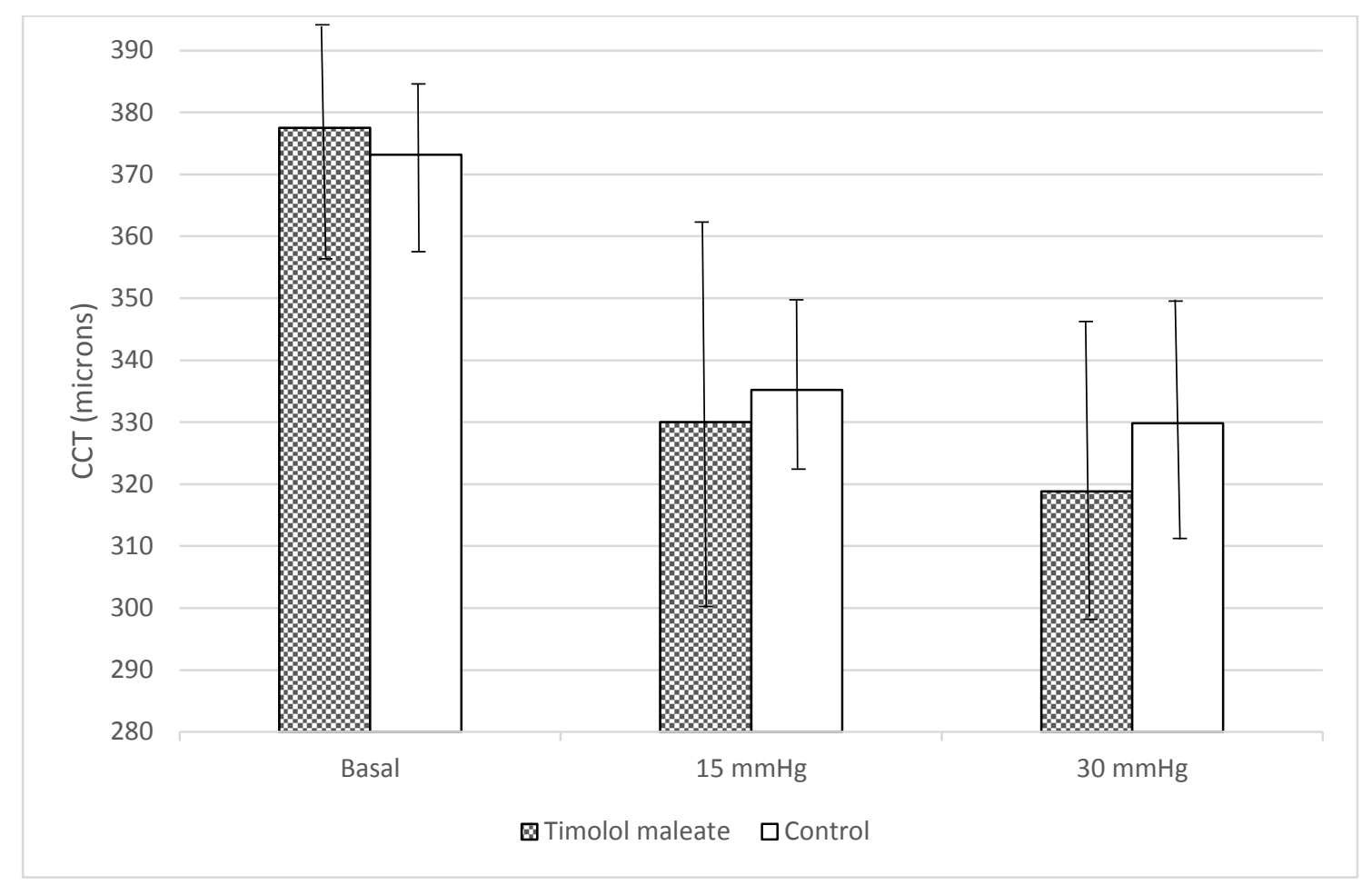

Fig. (2). The figure shows the differences in the average CCTs at baseline and after increasing the IOP levels to $15 \mathrm{and} 30 \mathrm{mmHg}$ between the control and treated groups ( $p=0.002$ basal $v s 15 \mathrm{mmHg}$ for both groups, and $p=0.1$ for CCT at $15 \mathrm{mmHg} v s 30 \mathrm{mmHg}$ in the study group and $p=0.5$ for the same comparison in the control eyes). The error bars represent the standard deviation. The differences between the CCT values between the study and control groups are not statistically significant $(p=0.5, p=0.6$, and $p=0.3$ at basal, $15 \mathrm{mmHg}$ and $30 \mathrm{mmHg}$, respectively).

\section{DISCUSSION}

In the current study, we did not find a significant difference between groups in either the basal CCT or the CCT decrease in response to IOP increases to 15 and $30 \mathrm{mmHg}$.

The current results agreed with previous reports that do not find a change in CCT after treatment with timolol maleate. Viswanathan et al. [20] reported no significant reduction of the CCT in eyes treated with beta-blockers, and other studies reported no significant changes in the CCT after 6 and 12 months, respectively [21, 22]. Nevertheless, another study found a reversible increase in the CCT [23]. In that study, the maximal increase in the CCT after topical administration of beta-blockers occurred after 9 days, and afterwards the CCT returned to its basal value. Therefore, it makes sense that in our study in which we measured the CCT after 1 month of topical treatment that we found no change in the CCT in study eyes compared with control eyes.

However, we found that the CCT decreased when the IOP increased and that the higher the IOP value the greater the CCT decrease was [2]. This agreed with the results of other studies [7]. The findings of the current study suggest that when the IOP increases, the stromal lamellae are compressed, probably because some fluid is expressed out of the corneal stroma [24]. Another explanation for the IOP-related decrease in the CCT could be that some degree of dehydration might have occurred during the experiment. Nevertheless, topical lubricant eye drops were used, and both eyes of each rabbit were randomized to be the first or the last to be examined, makes this potential confounding factor 
unlikely to bias our results.

The current study did not find a significant difference between both groups in the responses of the CCT to IOP increases. These results differ from those obtained previously in which we used the same study design but instilled PG analogues instead of timolol [2]. In another previous study, we observed that corneas treated with travoprost had a greater IOP-induced decrease in CCT from baseline than the control eyes. A possible explanation for this different behavior could have been the lower hypotensive effect of timolol than PG analogues [14], but we do not believe this is the case given the different response to hypotensive drugs in rabbit eyes compared with humans. In fact, the IOPs were similar in the current timolol maleate-treated eyes and the travoprost-treated eyes in the previous study (10.0 \pm 3.6 $\mathrm{mmHg}$ and $10.50 \pm 0.83 \mathrm{mmHg}$, respectively), so it seems unlikely that differences in the basal IOP could have affected the corneal response.

A possible explanation that could explain the different behavior of timolol-treated eyes compared with PG-treated eyes is that PGs not only reduce the IOP but also stimulate the local synthesis of Matrix Metalloproteinases (MMPs) in treated eyes [24]. The MMPs are a family of enzymes that degrade collagen types I, II, III, and IV [25, 26]. Considering that the corneal stroma has collagen types I, II, IV, and V [27 - 29] it is reasonable in our minds to consider that the corneal stroma might become less rigid after treatment with these drugs. However, topical beta-blockers that lower the IOP and reduce aqueous humour production by the ciliary epithelium $[23,30,31]$ would not directly affect the corneal stroma, so the degree of corneal compression induced by a sudden IOP increase would remain unchanged. Thus, a plausible explanation for the current findings is that up-regulation of MMPs in the corneal stroma caused by PG analogues might directly affect the corneal biomechanical behaviour [13] that is absent after timolol treatment.

Evaluation of the corneal biomechanical properties is becoming increasingly important in glaucoma. Different methods are used to analyze the corneal biomechanical behaviour [32 - 34]. Analysis of the corneal strain (thickness change) in response to a sudden IOP increase is a sensitive method to detect differences between the different responses of the corneal stromal bed and the laser in situ keratomileusis flap in enucleated human eyes [35]. Other methods are more suitable for measuring the corneal biomechanical properties in vivo, such as the ORA, which provides the $\mathrm{CH}$ and the corneal resistance factor, which represent the corneal viscoelastic response to air. The evaluations of the changes in $\mathrm{CH}$ after PG analogue treatment in humans are consistent with the current findings. We found that PG-treated corneas increase the $\mathrm{CH}$, which is unrelated to the drug-induced IOP decrease, thus further supporting the hypothesis that PG analogue treatment directly affects the corneal biomechanical behavior independent on the hypotensive effect [36]. The clinical relevance of this finding is that it might well be that treatment with PG analogues may be an artifact for tonometry, and thus there is the theoretical possibility that the hypotensive effect of these drugs may be over or underestimated. It is evident that this is just a speculation that needs further specifically designed studies to be tested.

A limitation of the current study was that the results in animals are not easily directly applicable to humans. Nevertheless, we believe that the finding that lowering the IOP using topical hypotensive drugs per se does not affect the biomechanical behaviour of the cornea unless the drug used has some direct effect on the collagen is correct, at least in rabbits. It is evident that only studies performed in humans can verify if the human cornea shows the same type of response than the rabbit one.

\section{CONCLUSION}

In summary, rabbit corneas treated with topical timolol maleate do not show a strain response to acute IOP increases that differs from that in control eyes. This is in contrast with the previously reported [2] finding that rabbit corneas treated with PG analogues have a greater decrease in CCT in response to a sudden IOP increase. Our findings suggested that PGs may induce changes in the corneal biomechanical properties independent of their hypotensive IOP, at least in rabbits.

Further studies are needed to clarify the possible changes in the strain properties of the cornea induced by antiglaucomatous therapy and the consequences that these changes might have on IOP measurements in these eyes and to determine if our findings are applicable to other species, such as humans.

\section{LIST OF ABBREVIATIONS}

$\begin{array}{lll}\text { IOP } & = & \text { Intraocular Pressure } \\ \text { GAT } & = & \text { Goldmann Applanation Tonometry } \\ \text { CCT } & = & \text { Central Corneal Thickness }\end{array}$




$\begin{array}{lll}\text { ORA } & = & \text { Ocular Response Analyzer } \\ \text { CAIs } & = & \text { Carbonic Anhydrase Inhibitors } \\ \text { ICP } & = & \text { Intrastomal Corneal Pressure } \\ \text { PG } & = & \text { Prostaglandin } \\ \text { CH } & = & \text { Corneal Hysteresis } \\ \text { MMPs } & = & \text { Metalloproteinases }\end{array}$

\section{FUNDING}

Supported in part by Grant number 11-01 from Fundación para la Investigación Biomédica del Hospital Universitario Príncipe de Asturias.

\section{ETHICS APPROVAL AND CONSENT TO PARTICIPATE}

This study was approved by the Institutional Review Board, Comité de Ética en Investigación Clínica of the "Hospital Universitario Príncipe de Asturias.

\section{HUMAN AND ANIMAL RIGHTS}

No Humans were used in this research. All animal research procedures followed were in accordance with the current regulations on experimentation and animal protection of the Government of Spain (RD 53/2013) and the recommendations of the Council of Europe agreement (ETS 123).

\section{CONSENT OF PUBLICATION}

Not applicable.

\section{CONFLICT OF INTERESTS}

The authors report no conflicts of interest. The authors alone are responsible for the content and writing of the paper.

\section{ACKNOWLEDGEMENTS}

Cristina Sanchez Barahona: Performed study, Collected data, wrote paper.

Gema Bolívar: Designed study, analyzed data, wrote paper.

Dimitrios G. Mikropoulos: Analyzed data, wrote paper.

Anastasios G. Konstas: Analyzed data, wrote paper.

Miguel A. Teus: Design study, analyzed data, wrote paper.

\section{REFERENCES}

[1] Cook C, Foster P. Epidemiology of glaucoma: What's new? Can J Ophthalmol 2012; 47(3): 223-6. [http://dx.doi.org/10.1016/j.jcjo.2012.02.003] [PMID: 22687296]

[2] Bolívar G, Teus M, Arranz-Marquez E. Effect of acute increases of intraocular pressure on corneal pachymetry in eyes treated with travoprost: An animal study. Curr Eye Res 2011; 36(11): 1014-9.

[http://dx.doi.org/10.3109/02713683.2011.608239] [PMID: 21942300]

[3] Doughty MJ, Zaman ML. Human corneal thickness and its impact on intraocular pressure measures: A review and meta-analysis approach. Surv Ophthalmol 2000; 44(5): 367-408. [http://dx.doi.org/10.1016/S0039-6257(00)00110-7] [PMID: 10734239]

[4] Herndon LW, Weizer JS, Stinnett SS. Central corneal thickness as a risk factor for advanced glaucoma damage. Arch Ophthalmol 2004; 122(1): 17-21. [http://dx.doi.org/10.1001/archopht.122.1.17] [PMID: 14718289]

[5] Liu J, Roberts CJ. Influence of corneal biomechanical properties on intraocular pressure measurement: Quantitative analysis. J Cataract Refract Surg 2005; 31(1): 146-55.

[http://dx.doi.org/10.1016/j.jcrs.2004.09.031] [PMID: 15721707]

[6] Arranz-Marquez E, Bolivar G, Piñero DP, Konstas AG, Mikropoulos DG, Teus MA. Orbscan topography in primary open-angle glaucoma. Optom Vis Sci 2013; 90(10): 1098-103.

[http://dx.doi.org/10.1097/OPX.0000000000000019] [PMID: 23939294] 
[7] Dada T, Konkal V, Tandon R, Singh R, Sihota R. Corneal topographic response to intraocular pressure reduction in patients with vernal keratoconjunctivitis and steroid-induced glaucoma. Eye (Lond) 2007; 21(2): 158-63. [http://dx.doi.org/10.1038/sj.eye.6702136] [PMID: 16273087]

[8] Martínez-de-la-Casa JM, Rodríguez-Uña I, González-Pastor E, Díaz-Valle D, García-Feijóo J. Post-laser in situ keratomileusis refractive changes induced by glaucoma in the absence of keratectasia. Arch Soc Esp Oftalmol 2014; 89(10): 414-7. [PMID: 24269455]

[9] Huseynova T, Waring GO IV, Roberts C, Krueger RR, Tomita M. Corneal biomechanics as a function of intraocular pressure and pachymetry by dynamic infrared signal and Scheimpflug imaging analysis in normal eyes. Am J Ophthalmol 2014; 157(4): 885-93. [http://dx.doi.org/10.1016/j.ajo.2013.12.024] [PMID: 24388837]

[10] Eisenlohr JE, Langham ME, Maumenee AE. Manometric studies of the pressure-volume relationship in living and enucleated eyes of individual human subjects. Br J Ophthalmol 1962; 46(9): 536-48. [http://dx.doi.org/10.1136/bjo.46.9.536] [PMID: 18170811]

[11] Pallikaris IG, Kymionis GD, Ginis HS, Kounis GA, Tsilimbaris MK. Ocular rigidity in living human eyes. Invest Ophthalmol Vis Sci 2005; 46(2): 409-14. [http://dx.doi.org/10.1167/iovs.04-0162] [PMID: 15671262]

[12] Ford MR, Sinha Roy A, Rollins AM, Dupps WJ Jr. Serial biomechanical comparison of edematous, normal, and collagen crosslinked human donor corneas using optical coherence elastography. J Cataract Refract Surg 2014; 40(6): 1041-7. [http://dx.doi.org/10.1016/j.jcrs.2014.03.017] [PMID: 24767794]

[13] Costin BR, Fleming GP, Weber PA, Mahmoud AM, Roberts CJ. Corneal biomechanical properties affect Goldmann applanation tonometry in primary open-angle glaucoma. J Glaucoma 2014; 23(2): 69-74. [http://dx.doi.org/10.1097/IJG.0b013e318269804b] [PMID: 23603825]

[14] Terminology and Guidelines for Glaucoma. $4^{\text {th }}$ ed. Savona, Italy: Publicomm 2014.

[15] Inoue K, Okugawa K, Oshika T, Amano S. Influence of dorzolamide on corneal endothelium. Jpn J Ophthalmol 2003; 47(2): 129-33. [http://dx.doi.org/10.1016/S0021-5155(02)00667-6] [PMID: 12738544]

[16] Teus MA, Bolívar G, Alió JL, Lipshitz I. Short-term effect of topical dorzolamide hydrochloride on intrastromal corneal pressure in rabbit corneas in vivo. Cornea 2009; 28(2): 206-10. [http://dx.doi.org/10.1097/ICO.0b013e318188ad80] [PMID: 19158566]

[17] Bolívar G, Teus MA, Hernández-Verdejo JL. Short-term effect of topical brimonidine tartrate on intrastromal corneal pressure in rabbits. J Refract Surg 2010; 26(7): 533-5. [http://dx.doi.org/10.3928/1081597X-20100310-01] [PMID: 20349857]

[18] Panos GD, Konstantinidis A, Mendrinos E, Kozobolis V, Perente I, Gatzioufas Z. Effect of tafluprost $0.0015 \%$ on central corneal thickness in patients with primary open-angle glaucoma. Curr Eye Res 2013; 38(9): 977-82. [http://dx.doi.org/10.3109/02713683.2013.801495] [PMID: 23713521]

[19] Agarwal DR, Ehrlich JR, Shimmyo M, Radcliffe NM. The relationship between corneal hysteresis and the magnitude of intraocular pressure reduction with topical prostaglandin therapy. Br J Ophthalmol 2012; 96(2): 254-7. [http://dx.doi.org/10.1136/bjo.2010.196899] [PMID: 21436180]

[20] Viswanathan D, Goldberg I, Graham SL. Longitudinal effect of topical antiglaucoma medications on central corneal thickness. Clin Experiment Ophthalmol 2013; 41(4): 348-54. [http://dx.doi.org/10.1111/j.1442-9071.2012.02870.x] [PMID: 22958109]

[21] Lass JH, Khosrof SA, Laurence JK, Horwitz B, Ghosh K, Adamsons I. A double-masked, randomized, 1-year study comparing the corneal effects of dorzolamide, timolol, and betaxolol. Arch Ophthalmol 1998; 116(8): 1003-10. [http://dx.doi.org/10.1001/archopht.116.8.1003] [PMID: 9715679]

[22] Lass JH, Eriksson GL, Osterling L, Simpson CV. Comparison of the corneal effects of latanoprost, fixed combination latanoprost-timolol, and timolol: A double-masked, randomized, one-year study. Ophthalmology 2001; 108(2): 264-71. [http://dx.doi.org/10.1016/S0161-6420(00)00531-5] [PMID: 11158797]

[23] Grueb M, Rohrbach JM. Effect of timolol on central corneal thickness. Eur J Ophthalmol 2013; 23(6): 784-8. [http://dx.doi.org/10.5301/ejo.5000307] [PMID: 23709328]

[24] Toris CB, Gabelt BT, Kaufman PL. Update on the mechanism of action of topical prostaglandins for intraocular pressure reduction. Surv Ophthalmol 2008; 53(Suppl. 1): S107-20. [http://dx.doi.org/10.1016/j.survophthal.2008.08.010] [PMID: 19038618]

[25] Sivak JM, Fini ME. MMPs in the eye: Emerging roles for matrix metalloproteinases in ocular physiology. Prog Retin Eye Res 2002; 21(1): $1-14$. [http://dx.doi.org/10.1016/S1350-9462(01)00015-5] [PMID: 11906808]

[26] Wong TT, Sethi C, Daniels JT, Limb GA, Murphy G, Khaw PT. Matrix metalloproteinases in disease and repair processes in the anterior segment. Surv Ophthalmol 2002; 47(3): 239-56. [http://dx.doi.org/10.1016/S0039-6257(02)00287-4] [PMID: 12052410] 
[27] Marshall GE, Konstas AG, Lee WR. Immunogold fine structural localization of extracellular matrix components in aged human cornea. I. Types I-IV collagen and laminin. Graefes Arch Clin Exp Ophthalmol 1991; 229(2): 157-63. [http://dx.doi.org/10.1007/BF00170550] [PMID: 2044978]

[28] Marshall GE, Konstas AG, Lee WR. Collagens in ocular tissues. Br J Ophthalmol 1993; 77(8): 515-24. [http://dx.doi.org/10.1136/bjo.77.8.515] [PMID: 8025051]

[29] Meek KM, Boote C. The organization of collagen in the corneal stroma. Exp Eye Res 2004; 78(3): 503-12. [http://dx.doi.org/10.1016/j.exer.2003.07.003] [PMID: 15106929]

[30] Grueb M, Bartz-Schmidt KU, Rohrbach JM. Adrenergic regulation of cAMP/protein kinase A pathway in corneal epithelium and endothelium. Ophthalmic Res 2008; 40(6): 322-8. [http://dx.doi.org/10.1159/000150446] [PMID: 18688175]

[31] Walkenbach RJ, Chao WT, Bylund DB, Gibbs SR. Characterization of beta-adrenergic receptors in fresh and primary cultured bovine corneal endothelium. Exp Eye Res 1985; 40(1): 15-21. [http://dx.doi.org/10.1016/0014-4835(85)90104-6] [PMID: 2984031]

[32] Ang GS, Bochmann F, Townend J, Azuara-Blanco A. Corneal biomechanical properties in primary open angle glaucoma and normal tension glaucoma. J Glaucoma 2008; 17(4): 259-62 [http://dx.doi.org/10.1097/IJG.0b013e31815c3a93] [PMID: 18552609]

[33] Bonatti JA, Bechara SJ, Carricondo PC, Kara-José N. Proposal for a new approach to corneal biomechanics: Dynamic corneal topography. Arq Bras Oftalmol 2009; 72(2): 264-7. [http://dx.doi.org/10.1590/S0004-27492009000200028] [PMID: 19466344]

[34] Elsheikh A, Alhasso D, Kotecha A, Garway-Heath D. Assessment of the ocular response analyzer as a tool for intraocular pressure measurement. J Biomech Eng 2009; 131(8): 081010. [http://dx.doi.org/10.1115/1.3148462] [PMID: 19604022]

[35] Dawson DG, Schmack I, Holley GP, Waring GO III, Grossniklaus HE, Edelhauser HF. Interface fluid syndrome in human eye bank corneas after LASIK: Causes and pathogenesis. Ophthalmology 2007; 114(10): 1848-59. [http://dx.doi.org/10.1016/j.ophtha.2007.01.029] [PMID: 17908592]

[36] Bolívar G, Sánchez-Barahona C, Teus M, et al. Effect of topical prostaglandin analogues on corneal hysteresis. Acta Ophthalmol 2015; 93(6): e495-8. [http://dx.doi.org/10.1111/aos.12689] [PMID: 25722009]

(C) 2018 Sánchez-Barahona et al.

This is an open access article distributed under the terms of the Creative Commons Attribution 4.0 International Public License (CC-BY 4.0), a copy of which is available at: (https:/creativecommons.org/licenses/by/4.0/legalcode). This license permits unrestricted use, distribution, and reproduction in any medium, provided the original author and source are credited. 